\title{
Recurrent respiratory distress associated with carbamazepine overdose
}

\author{
F.A. Wilschut*, N.A.M. Cobben*, F.B.J.M. Thunnissen**, \\ R.J.S. Lamers ${ }^{+}$, E.F.M. Wouters*, M. Drent*
}

Recurrent respiratory distress associated with carbamazepine overdose. F.A. Wilschut, N.A.M. Cobben, F.B.J.M. Thunnissen, R.J.S. Lamers, E.F.M. Wouters, M. Drent. (CERS Journals Ltd 1997.

ABSTRACT: Acute interstitial pneumonia or diffuse alveolar damage is uncommon as an adverse reaction to carbamazepine therapy. We report the case of a 36 yr old woman, who developed respiratory failure after auto-intoxication with carbamazepine. Analysis, including bronchoalveolar lavage and lung tissue biopsy, suggested diffuse alveolar damage due to carbamazepine.

Eur Respir J 1997; 10: 2163-2165.
Depts of *Pulmonology, **Pathology and +Radiology, University Hospital of Maastricht, Maastricht, The Netherlands.

Correspondence: M. Drent, University Hospital Maastricht, Dept of Pulmonology, P.O. Box 5800, 6202 AZ Maastricht, The Netherlands

Keywords: Adverse effects, carbamazepine, drug-induced pneumonitis, lactate dehydrogenase

Received: March 61997

Accepted after revision May 311997
Carbamazepine is widely used in the treatment of epilepsy, neuralgic pain and bipolar affective disorders. The drug is a carbamylated iminostilbene, structurally related to the tricyclic antidepressants [1]. A variety of complications have been reported, including neurological adverse effects, hypersensitivity with eosinophilia, vasculitis and systemic lupus erythematosus-like syndromes, gastro-intestinal and hepatic side-effects, haematological toxicity, cardiac toxicity, and renal, endocrinological and psychic adverse effects $[1,2]$. Pulmonary toxicity is rare, but has been reported previously [3-9]. It occurs mostly 1-3 months after introduction of the drug, and is manifested by fever, dry cough and dyspnoea, with or without skin rash and eosinophilia [3-9]. The chest radiograph usually shows bilateral interstitial infiltrates [3, 4, 6-9]; pleural effusion was reported once [9].

We report the occurrence of acute pneumonia after ingestion of a massive dose of carbamazepine.

\section{Case report}

A 36 yr old Caucasian female was admitted to a local hospital, after she had attempted suicide by swallowing 60 tablets of $200 \mathrm{mg}$ carbamazepine, that had been prescribed to her 9 yr old son, who suffered from epilepsy. Her medical history was unremarkable, except for a hysterectomy. She smoked 25 cigarettes $\cdot \mathrm{day}^{-1}$, the number of pack-years approximated 20.

At admission, $5 \mathrm{~h}$ after the ingestion, she was unconscious. Neurological examination revealed a hypertonic patient with areflexia, and intermittent extensor spasms. After the usual emergency procedures including intubation and gastric aspiration, a chest radiograph, electrocardiography, and routine blood analysis were performed. No abnormalities were found. The plasma level for car- bamazepine was $85 \mathrm{mg} \cdot \mathrm{L}^{-1}$ (therapeutic plasma level: 5-10 $\left.\mathrm{mg} \cdot \mathrm{L}^{-1}\right)$.

Despite haemodialysis, the patient developed progressive respiratory failure $48 \mathrm{~h}$ after admission, and was transferred to our hospital for mechanical ventilation. Chest radiography showed confluent alveolar shadows throughout both lungs (fig. 1) and high resolution computed tomography (HRCT) showed extensive bilateral ground-glass opacity, ill-defined small nodular opacities and a small amount of bilateral pleural effusion. No

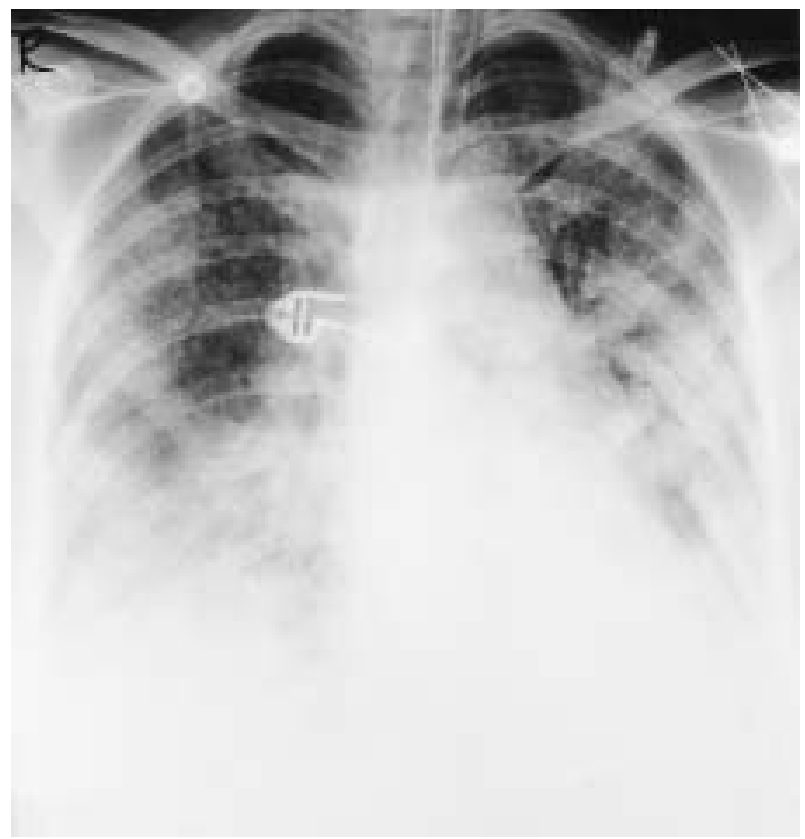

Fig. 1. - Chest radiograph 4 days after the first massive overdose of carbamazepine showing confluent alveolar shadows throughout both lungs. 
bacteria were seen on Gram-stained preparations of bronchoalveolar lavage fluid (BALF). Cultures of the BALF and blood were negative. No additional BALF analysis was performed on the minimal amount of fluid obtained. In the serum, lactate dehydrogenase (LDH) activity was increased to $1230 \mathrm{U} \cdot \mathrm{L}^{-1}$ (reference range 200-450 U.L ${ }^{-1}$ ). Except for low protein levels (serum albumin $19 \mathrm{~g} \cdot \mathrm{L}^{-1}$ ), all other laboratory tests were within normal limits. Eosinophilia was not present.

Thirteen days after first admission, as the clinical situation did not improve, an open lung biopsy was performed. Histologically, diffuse alveolar damage (DAD) in the proliferative stage was seen (fig. 2). The patient was treated with supportive care, and no steroids were given. Nineteen days after admission, she was extubated. Three months later, lung function parameters were within normal limits, the transfer factor of the lung for carbon monoxide (TL,CO) was $61 \%$ of predicted, and the specific diffusing capacity $(\mathrm{KCO})$ was $62 \%$ pred. Eight months later, the values for $T \mathrm{~L}, \mathrm{CO}$ and $K \mathrm{CO}$ were improved to 77 and $98 \%$ pred, respectively.

Fifteen months after the first admission, the patient was re-admitted to our hospital after a new overdose of carbamazepine. The clinical features and course were quite similar to the episode described above. The peak plasma level of carbamazepine was $52 \mathrm{mg} \cdot \mathrm{L}^{-1}$. Again, haemodialysis was required. BALF analysis revealed a total cell amount of $35.3 \times 10^{4}$ cells $\cdot \mathrm{mL}^{-1}$; (reference value for smokers $29.2 \pm 3.3 \times 10^{4}$ cells $\cdot \mathrm{mL}^{-1}$ ), with a predominance of neutrophils $(89.4 \%$; reference value for smokers $1.2 \pm 1.6 \%$ ) [10]. Again, serum LDH was increased (2160 U.L-1; fig. 3), with a predominant increase of $\mathrm{LDH}_{4}$ and $\mathrm{LDH}_{5}$ isoenzymes in serum $\left(\mathrm{LDH}_{1} 6.8 \%\right.$, reference value $19-30 \%$; $\mathrm{LDH}_{2} 17.8 \%$, reference value $32-48 \% ; \mathrm{LDH}_{3} 21.9 \%$, reference value $12-22 \% ; \mathrm{LDH}_{4}$ $20.5 \%$, reference value $4-11 \%$; and $\mathrm{LDH}_{5} 32.9 \%$, reference value 5-13\%), as well as in the BALF $\left(\mathrm{LDH}_{1}\right.$ $3.6 \%$, reference value $8-35 \% ; \mathrm{LDH}_{2} 9.0 \%$, reference value $15-30 \% ; \mathrm{LDH}_{3} 21.2 \%$, reference value $22-30 \%$; $\mathrm{LDH}_{4} 31.7 \%$, reference value 14-27\%; and $\mathrm{LDH}_{5}$ $34.4 \%$, reference value 6-14\%). Again, serum protein levels were low, with a serum albumin of $16.5 \mathrm{~g} \cdot \mathrm{L}^{-1}$. During this episode of respiratory failure, the patient

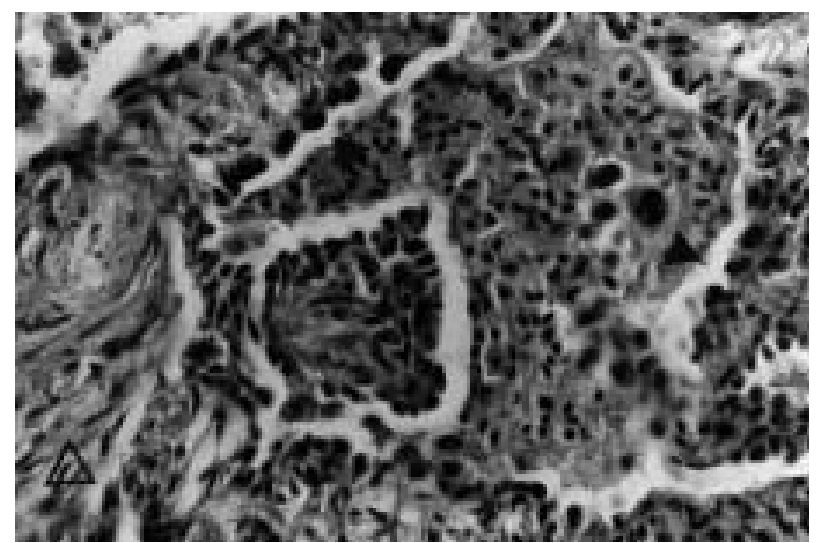

Fig. 2. - Open lung biopsy specimen of a patient with carbamazepine intoxication. Type II pneumocytes line the alveolar wall (closed arrow heads). The interstitium shows a proliferation of fibroblastic cells (open arrow head). The alveolar space is here filled with macrophages. This picture is consistent with the proliferative phase of diffuse alveolar damage. (Haematoxylin-eosin stain; internal scale bar $=25 \mu \mathrm{M})$.

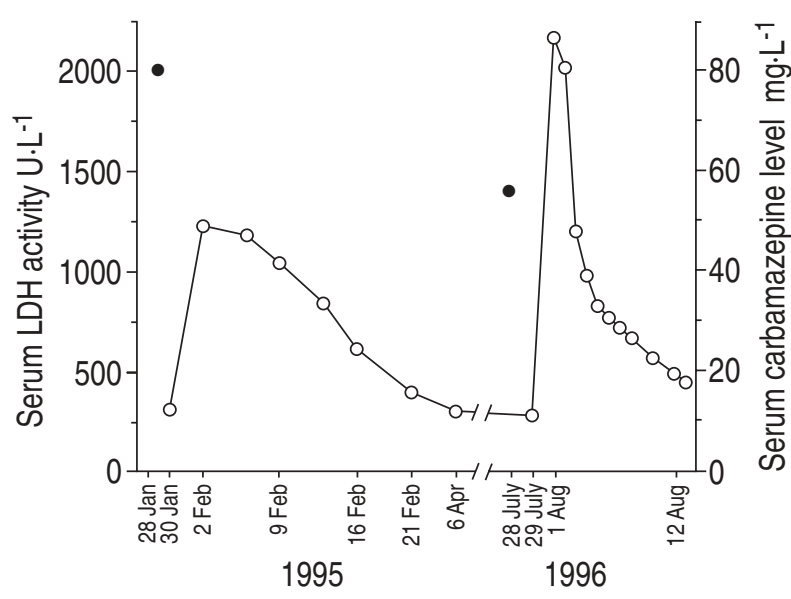

Fig. 3. - Serum lactate dehydrogenase (LDH) activity pattern and maximum serum carbamazepine levels in the presented patient who attempted suicide twice with a single overdose of carbamazepine on January 1, 1995 and July 28, 1996, respectively. o : LDH; • : carbamazepine.

was mechanically ventilated for 10 days. Corticosteroids (prednisone $1 \mathrm{mg} \cdot \mathrm{kg}^{-1}$ ) were started 7 days after the overdose, and gradually tapered off over 10 days. The patient declined psychiatric treatment, and left the hospital 2 days after extubation. Further follow-up was not possible.

\section{Discussion}

The patient presented in this case report, on two occasions developed a life-threatening respiratory failure after a single overdose of carbamazepine.

The mechanism of lung injury by long-term use of carbamazepine has been suspected to be an immunemediated hypersensitivity, on the basis of in vitro lymphocyte-stimulation tests [11]. The mechanisms for acute carbamazepine toxicity, however, are unknown.

In acute processes such as DAD, three stages can be distinguished in sequence: the so-called initial, exudative and proliferative stages. KITSON and WAUCHOB [12] reported pulmonary oedema after a massive overdose of carbamazepine. They suggested that, in massive overdose, the antidiuretic effect of the drug may be sufficient to induce pulmonary oedema, a hypothesis supported by their patient's low protein levels in blood. Our patient also demonstrated low protein levels during each of the two episodes, 66 and $96 \mathrm{~h}$ after ingestion, respectively. Similar adult respiratory distress syndrome-like pictures have been described following overdosage of amitriptyline [13, 14], haloperidol [15], and after exposure to propyl-thiouracil [16].

The histological examination of the lung biopsy specimen in our case revealed signs of an acute interstitial pneumonia (proliferative stage), compatible with the relatively short time span (13 days) after the single exposure to the toxic agent. In contrast, in three other case reports describing histological examination, the tissue was obtained by bronchial biopsy after an exposure of 3 months or more to carbamazepine [4, 8, 9]. The histological changes found in those cases of chronic carbamazepine dosage included chronic inflammatory infiltrates with plasma cells [8] and eosinophils [4], interstitial fibrosis [4], and granulomas [9]. 
Our patient demonstrated high LDH levels in serum during both episodes of carbamazepine overdosage (fig. 3 ). Elevations of the LDH activity in lung tissue and serum, respectively, have been noted in many cases with a history of exposure to pneumotoxicants [17]. Lung parenchyma cells or local inflammatory cells including alveolar macrophages and polymorphonuclear neutrophils may be a potential source of LDH release [18]. This local increase of the LDH level may result in leakage of LDH from the pulmonary interstitium to the vascular system.

In conclusion, acute interstitial pneumonia is an uncommon, but serious, adverse reaction to carbamazepine. This case demonstrates that single exposure to an extremely high dose may lead to a life-threatening respiratory failure with diffuse alveolar damage.

Acknowledgements: The authors gratefully acknowledge $\mathrm{Sj}$. Sc. Wagenaar for his advice and critical comments during preparation of the manuscript. The authors wish to thank Novartis Pharma BV The Netherlands for providing financial support for the full-colour print.

\section{References}

1. Gram L. Carbamazepine. Toxicity. In: Levy RH, ed. Antiepileptic Drugs. New York, Raven, 1989; pp. 555-565.

2. Anonymous. Case Records of the Massachusetts General Hospital. Case 26. 1996. N Engl J Med 1996; 335: 577-584.

3. Cullinan SA, Bower GC. Acute pulmonary hypersensitivity to carbamazepine. Chest 1975; 68: 580-581.

4. Stephan WC, Parks RD, Tempest B. Acute hypersensitivity pneumonitis associated with carbamazepine. Chest 1978; 74: 463-464.

5. Lee T, Cochrane GM, Amlot BR. Pulmonary eosinophilia and asthma associated with carbamazepine. $\mathrm{Br} \mathrm{Med}$ $J$ 1981; 282: 440.

6. De Swert LF, Ceuppens JL, Teuwen D, Wijndale L, Casaer P, Daele MC. Acute interstitial pneumonitis and carbamazepine therapy. Acta Paediatr Scand 1984; 73: 285-288.

7. Barreiro B, Manresa F, Valldeperas J. Carbamazepine and the lung. Eur Respir J 1990; 3: 930-931.

8. Takahashi N, Aizawa H, Takata S, et al. Acute interstitial pneumonitis induced by carbamazepine. Eur Respir J 1993; 6: 1409-1411.

9. King GG, Barnes DJ, Hayes MJ. Carbamazepine-induced pneumonitis. Med J Aust 1994; 160: 126-127.

10. Drent M, van Nierop MAMF, Gerritsen FA, Wouters EFM, Mulder PGH. A computer program using BALFanalysis results as a diagnostic tool in interstitial lung diseases. Am J Respir Crit Care Med 1996; 153: 736741.

11. Houwerzijl J, Gast GC, Nater JP, Esselink MT, Nieweg HO. Lymphocyte-stimulation tests and patch tests in carbamazepine hypersensitivity. Clin Exp Immunol 1977; 29: 272-277.

12. Kitson GE, Wauchob TD. Pulmonary oedema following carbamazepine overdose. Anaesthesia 1988; 43: 967-969.

13. Marshall A, Moore K. Pulmonary disease after amitriptyline overdose. Br Med J 1973; i: 716-717.

14. Lindström FD, Flodmark O, Gustafsson B. Respiratory distress syndrome and thrombotic, non-bacterial endocarditis after amitriptyline overdosage. Acta Med Scand 1977; 202: 203-212.

15. Mahutte CK, Nakasato SK, Light RW. Haloperidol and sudden death due to pulmonary edema. Arch Intern Med 1982; 142: 1951-1952.

16. Chevrolet JC, Guelpa G, Schifferli JA. Recurrent adult respiratory distress-like syndrome associated with propylthiouracil therapy. Eur Respir J 1991; 4: 899-901.

17. Drent M, Cobben NAM, Henderson RF, Jacobs JA, Wouters EFM, van Dieijen-Visser MP. BAL fluid LDH activity and LDH isoenzyme pattern in lipoid pneumonia caused by an intravenous injection of lamp oil. Eur Respir J 1996; 9: 2416-2418.

18. Drent M, Cobben NAM, Henderson RF, Wouters EFM, van Dieijen-Visser MP. Usefulness of lactate dehydrogenase and its isoenzymes as indicators of lung damage or inflammation. Eur Respir J 1996; 9: 1736-1742. 